\title{
AS CRIANÇAS PÓS-MODERNAS: O QUE É PRECISO PARA ENTENDER MELHOR O PÓS-MODERNO? LYOTARD EXPLICARÁ ÀS CRIANÇAS
}

\author{
Alexandre Lopes Campelo \\ Universidade Federal do Piauí/UFPI Brasil
}

\begin{abstract}
RESUMO: O artigo reuni considerações acerca de algumas cartas que JeanFrançois Lyotard escreveu a propósito do debate pós-moderno em seu livro $\mathrm{O}$ pós-moderno explicado às crianças, relacionando-as com os argumentos da obra Condição pós-moderna para verificarmos uma possível defesa de ruptura entre modernidade e pós-modernidade, tal reunião das considerações contidas nas cartas, que J. F. Lyotard escreveu, a propósito do debate pós-moderno nos fará mostrar que não há uma mudança considerável das regras do discurso científico na pós-modernidade, comparadas às da modernidade, elas apenas se constituíram mais explícitas. O trabalho verifica ainda que J. F. Lyotard pondera a favor, não de uma ruptura ou simples sucessão de épocas, mas declara existir uma nova direção depois da anterior.
\end{abstract}

Palavras-chave: Modernidade, pós-modernidade, totalitarismo, legitimidade, formação, filosofia.

\section{CHILDREN POSTMODERN: WHAT IS NEEDED TO BETTER UNDERSTAND THE POSTMODERN? LYOTARD EXPLAIN TO CHILDREN}

\footnotetext{
ABSTRACT: Article gathered considerations about some letters that Jean-François Lyotard wrote about the postmodern debate in his book The postmodern explained to children, relating them to the arguments of the work postmodern condition to verify a possible defense rupture between modernity and postmodernity, such a meeting of the considerations contained in the letters, that J. F. Lyotard wrote, concerning the postmodern debate will show us that there is a considerable change of the rules of scientific discourse in postmodernity, compared to
} 
modernity, they only constituted more explicit. The paper also notes that J. F. Lyotard weighs in favor, not a break or simple succession of seasons, but says there is a new direction after the previous one.

Keywords: Modernity, postmodern, totalitarianism, legitimacy, training, philosophy.

Neste artigo reunimos considerações acerca de algumas cartas que J. F. Lyotard escreveu a propósito do debate pós-moderno em seu livro O pós-moderno explicado às crianças ${ }^{1}$. Nosso objetivo é relacioná-las com os argumentos da obra Condição pós-moderna para verificarmos uma possível defesa de ruptura entre modernidade e pós-modernidade.

De acordo com a nota do editor francês, não foi fácil conseguir a autorização para tal publicação, contudo, os argumentos utilizados visavam persuadir o autor de que era preciso ilibá-lo de acusações que o caracterizavam como irracional, neoconservador, terrorista intelectual, liberal simplório, niilista, dentre outras atribuições. Mas o que nos mostra a referida nota é que J. F. Lyotard não tinha nenhuma preocupação com as críticas de seus adversários, pois, segundo ele, essas críticas advinham não de uma leitura de seus escritos, ou mesmo de argumentos ad rem, ao contrário, seus adversários operavam via argumentos ad hominem, logo contra-argumentar sob essas condições não merecia nenhuma disposição. J. F. Lyotard relutava em publicar tais cartas alegando que os textos eram ingênuos, a ponto de não oferecerem nenhuma contribuição para o debate acerca do pós-moderno, que ele próprio via de maneira nebulosa.

Todavia, o argumento que mudou a opinião de J. F. Lyotard consistia em afirmar que, mesmo sendo pueris e inacabados, os textos contribuíam com o debate, pois traziam o pressentimento de que algo estava se transformando dentro da história contemporânea. Assim, são por essas razões que consideramos a discussão de tais textos extremamente valiosa para darmos continuidade ao processo de análise de uma possível ruptura entre modernidade e pós-modernidade dentro da condição pós-moderna. Para isso, exporemos as considerações que nosso autor constrói acerca da modernidade e da pós-modernidade, suas críticas ao totalitarismo, a questão da legitimidade, e, finalmente, seu entendimento sobre a formação filosófica.

Em Resposta à pergunta: o que é o pós-moderno?, numa das dez cartas, J. F. Lyotard projeta seu estarrecimento diante das leituras que o acompanham, afirmando, enfaticamente: "estamos num período de permissividade, e é do ar do

1. O Pós-moderno explicado às crianças: correspondência 1982-1985, da Editora Publicações Dom Quixoteque/Portugal, 2ª edição de 1993. 
tempo que eu falo" 2 . Dentre tantas leituras, "li um pensador reputado que defende a modernidade contra aqueles a quem ele chama os neoconservadores, e que pretendem, julga ele, sob o estandarte do pós-modernismo, desembaraçarse do projecto moderno que ficou inacabado, o das Luzes"3. De acordo com J. F. Lyotard, J. Habermas pensava que se a modernidade falhou foi por considerar que a totalidade da vida fragmentou-se em especialidades e o indivíduo concreto vive a desestrutura. A solução para isso, segundo J. Habermas, seria uma aproximação do discurso com o conhecimento da ética, com a política, o que significa uma "passagem para a unidade da experiência" ${ }^{4}$. Todavia, a questão colocada por J. F. Lyotard é saber que unidade é essa pensada por J. Habermas. Assim questiona:

O fim visado pelo projeto moderno será a constituição de uma unidade sóciocultural no seio da qual todos os elementos da vida cotidiana e do pensamento venham ocupar seu lugar, como num todo orgânico? Ou será que a passagem que é preciso abrir entre os jogos de linguagem heterogênios, os do conhecimento, da ética, da política é de uma outra ordem? E, nesse caso, como seria ele capaz de realizar a sua síntese efetiva? 5

Essas questões levam J. F. Lyotard a julgar que a pós-modernidade impõe uma revisão da Aufklärung, ou seja, questiona a noção de um fim unitário da história e do sujeito. Tal crítica iniciada por L. Wittgenstein e W. Adorno, por exemplo, é considerado por J. Habermas, segundo J. F. Lyotard, sinal de neoconservadorismo.

E o realismo?

Existe um desafio sobre o qual J. F. Lyotard fala a partir da arte. Segundo ele, há convites os mais diversos para "suspender a experimentação artística uma mesma chamada à ordem, um desejo de unidade, de identidade, de segurança e de popularidade" ${ }^{\prime \prime}$, no sentido de encontrar público. Os efeitos de realidade se multiplicam, contudo, o capitalismo, segundo J. F. Lyotard, tem o poder de desrealizar os papéis da vida social "e as representações ditas 'realistas' já só podem evocar a realidade sob a forma da nostalgia ou da paródia como ocasião de sofrimento mais do que de satisfação" ${ }^{\prime \prime}$.

Para não tornar-se mero suporte, a arte deve recusar-se a usos terapêuticos. Aqueles que aceitam pôr em dúvida artes plásticas e narrativas, serão condena-

2. LYOTARD, J. F. 1993, p. 13.

3. op. cit., p. 14.

4. op. cit., p. 15.

5. Ibid.

6. op. cit., p. 16.

7. op. cit., p. 16-17. 
dos a não receber "credibilidade junto dos amadores preocupados com a realidade e identidade, e ficam sem audiência garantida" ${ }^{\prime}$. O realismo do qual J. F. Lyotard fala é impositor de um tipo de "boa" imagem e "boas" narrativas. A experimentação artística é atacada quando se manifesta a respeito das regras do belo.

O poder do capital produz um conformismo com o Kitsch, segundo J. F. Lyotard, "este realismo do 'seja lá o que for' é o dinheiro: faltando critérios estéticos, continua a ser possível e útil medir o valor das obras em função do lucro que se pode obter com elas. Este realismo acomoda-se a todas as tendências, como o capital a todas as 'necessidades', desde que as tendências e as necessidades tenham poder de compra" 9 .

De acordo com J. F. Lyotard, nem a ciência nem a indústria estão protegidas da suspeita relativa à realidade daquilo que a arte e a escrita não podem negar, da predominância da tecnociência, ou seja, da "subordinação maciça dos enunciados cognitivos à finalidade da melhor performance possível que é o critério técnico" ${ }^{\prime 10}$. Contudo, tanto o mecânico quanto o industrial, ao entrarem no campo reservado ao artístico, aqueles com origem no conhecimento científico e na economia capitalista, não fogem à regra "de que não há realidade que não seja atestada por um consenso entre parceiros sobre conhecimentos e compromissos"11. E mais, "este recuo é indispensável para que nasçam a ciência e o capitalismo"12. Para J. F. Lyotard, a modernidade, sem uma data definida, rígida, é inseparável "do enfraquecimento da crença e da descoberta do pouco de realidade da realidade, associada à invenção de outras realidades"13.

Diante da perspectiva de dizer o que é o sublime ${ }^{14} \mathrm{~J}$. F. Lyotard afirma que o sublime ocorre quando a imaginação falha ao "presentificar" a concordância com

\footnotetext{
8. op. cit., p. 18.

9. op. cit., p. 19-20.

10. op. cit., p. 20.

11. op. cit., p. 21.

12. Ibid.

13. Ibidem.
}

14. Na obra O Inumano (1997), J. F. Lyotard diz que o sublime é um sentimento contraditório, "prazer e dor felicidade e angústia, exaltação e depressão"(p. 98). Em outro momento do mesmo livro, J. F. Lyotard afirma que "O sublime será talvez o modo da sensibilidade artística que caracteriza o modernismo"(p. 99). Além disso, o sentimento do sublime, "cuja analítica I. Kant introduz sem qualquer justificação, o que não é hábito, possui a propriedade interessante de não ter uma comunicabilidade imediata. O sentimento do sublime manifesta-se quando falta a apresentação de formas livres. É compatível com o in-forme. É exatamente quando falta a imaginação que apresenta formas, que tal sentimento aparece. E este último deve passar pela mediação de uma idéia da razão a qual é a Idéia de liberdade. Achamos sublimes espetáculos que excedem qualquer apresentação verdadeira de uma forma, ou seja, onde se significa a superioridade do nosso poder de liberdade em relação ao manifestado no próprio espetáculo. Ao isolar o sublime, I. Kant salienta algo que está em relação direta com o problema da falência do espaço e do tempo. As formas livremente flutuantes que suscitavam o sentimento do belo 
um conceito. Segundo ele, temos, por exemplo, a "ideia do mundo (a totalidade daquilo que é), mas não temos a capacidade de dar um exemplo dele"15. São ideias como tantas outras "impresentificáveis"16. Por exemplo, a pintura moderna tem como propósito "fazer ver que há algo que se pode conceber e que não se pode ver nem fazer ver"17, ou seja, presentificar o que há de impresentificável.

A confirmação da negação da existência de uma ruptura entre modernidade e pós-modernidade surge com a resposta à seguinte pergunta feita e respondida por J. F. Lyotard: O que é então o pós-moderno? O pós-moderno "faz certamente parte do moderno, o diferendo é que na estética moderna há o sublime, ou seja, prazer e dor, segundo I. Kant"18. Tem uma consistência envolta em consolação e prazer. Mas o pós-moderno

seria aquilo que no moderno alega o 'impresentificável' na própria 'presentificação'; aquilo que se recusa à consolação das boas formas, ao consenso de um gosto que permitiria sentir em comum a nostalgia do impossível; aquilo que se investiga com 'presentificações'novas, não para as desfrutar, mas para melhor fazer sentir o que há de impresentificável'. Um artista, um escritor pós-moderno está na situação de um filósofo: o texto que escreve, a obra que realiza não são em princípio governadas por regras já estabelecidas, e não podem ser julgadas mediante um juízo determinante, aplicando a esse texto, a essa obra, categorias conhecidas. Estas regras e estas categorias são aquilo que a obra ou o texto procura. $\mathrm{O}$ artista e o escritor trabalham portanto sem regras, e para estabelecer as regras daquilo que foi feito. Daí que a obra e o texto tenham as propriedades do acontecimento, daí também que cheguem demasiado tarde para o seu autor, ou, e vem a dar no mesmo, que a sua preparação comece sempre demasiado cedo. Pós-moderno devia ser entendido segundo o paradoxo do futuro (pós) anterior $(\operatorname{modo})^{19}$.

De acordo com J. F. Lyotard, o que parece caracterizar a pós-modernidade é o acontecimento que é representado, se é que assim podemos afirmar, pelo impresentificável, ou seja, não compete à pós-modernidade fornecer realidade "mas inventar alusões ao concebível que não pode ser 'presentificado" 20 .

passam a faltar. De certo modo a questão do sublime está intimamente ligada ao que M. Heidegger chama de retirada do ser, retirada de doação. O acolhimento feito ao sensível, ou seja, ao significado encarnado no aqui-agora, antes de qualquer conceito, já não teria lugar, nem momento. Esta retirada significaria a nossa situação atual"(p. 117-118.).

15. LYOTARD, J. F. 1993, p. 22.

16. Ibid.

17. Ibidem.

18. op. cit., p. 21.

19. op. cit., p. 26.

20. op. cit., p. 27. 
Retomando questões já discutidas em A condição pós-moderna, J. F. Lyotard enfatiza em mais uma carta, Apostila às narrativas, o agravamento do cenário que subjaz a essa condição. Em A condição pós-moderna, J. F. Lyotard discute as metanarrativas e como elas marcaram a modernidade no sentido de fazer crer no progresso da tecnociência capitalista. De acordo com J. F. Lyotard, as narrativas não são mitos por procurarem legitimidade num ato original fundador, mas sim, porque visam a orientar todas as realidades humanas. O característico da modernidade é o projeto.

Contudo, no argumento de J. F. Lyotard, o projeto moderno, ou seja, aquele da realização da universalidade, não foi esquecido, mas sim destruído, segundo ele, uma das formas dessa destruição foi "Auschwitz", mas há uma outra destruição: a vitória da tecnociência capitalista, que destrói o projeto moderno ao tempo que faz crer realizá-lo. O que se obteve com os objetos trazidos pelas ciências e pelas tecnologias contemporâneas não veio acompanhado de mais liberdade ou de mais educação, nem de melhor distribuição de riqueza, ao contrário, acelerou o processo de deslegitimação já presente na modernidade. A fonte de legitimidade na história moderna, a partir de 1792, é o povo que não passa de uma ideia. O que acontece nas guerras é exatamente a disputa pela boa ideia de um determinado povo, em 'Auchwitz' todo um povo foi destruído. Conforme J. F. Lyotard, "é o crime que inaugura a pós-modernidade, crime de lesa-soberania, já não regicídio, mas populicídio (distinto dos etnocídios)"21.

As metanarrativas, diante do exposto acima, sofrem com sua credibilidade, já que, para J. F. Lyotard, essas narrativas têm a função de legitimar, o que não impede, depois dos questionamentos acerca delas, que as mesmas tenham desaparecido. Segundo J. F. Lyotard, em A condição pós-moderna, uma questão pungente é a identificação do conhecimento com a narrativa e, para um esclarecimento do que vimos até agora, J. F. Lyotard nos diz:

não é que a teoria seja mais objetiva do que a narrativa. A narrativa do historiador está submetida quase às mesmas regras de estabelecimento da realidade do que a do físico. Mas a história é uma narração que tem ainda por cima a pretensão de ser uma ciência, e não simplesmente um romance. Em contrapartida, a teoria científica não tem em princípio a pretensão de ser narrativa (embora a astrofísica contemporânea conte com gosto a história do cosmos desde o Big Bang). Por outras palavras, penso que hoje em dia é preciso distinguir regimes de frases diferentes e gêneros de discursos diferentes. Há na narratologia geral um elemento metafísico não criticado, uma hegemonia concebida a um gênero, o narrativo, sobre todos os outros, uma espécie de soberania das pequenas narrativas, que Ihe permitiria escapar à crise de deslegitimação. Escapam-lhe, é certo, mas é porque também não tem valor de legitima-

21. op. cit., p. 33 . 
ção. A prosa do povo, quero dizer: a sua prosa real, diz uma coisa e o seu contrário. 'Quem vê caras não vê corações' e 'o rosto é o espelho da alma'. Foi o romantismo que pensou que ela era consistente, orientada por uma tarefa de expressividade, de emancipação, de revelação de uma sageza. A pós-modernidade também é o fim do povo-rei das histórias ${ }^{22}$.

Finalmente, J. F. Lyotard traz-nos de volta para a percepção não só do sujeito humano, como daquilo que ele cria, recria e representa. A ciência, a técnica e a sociedade são constitutivos dessa natureza que o homem transforma e desestabiliza constantemente.

Em Missiva sobre a história universal, J. F. Lyotard nos mostra que o gênero narrativo não tem privilégio sobre todos os outros gêneros de discurso, tampouco na análise dos fenômenos humanos e menos ainda no trabalho filosófico. Afirma que em $A$ condição pós-moderna algumas das suas reflexões sucumbiram ao que ele denominou de 'aparência transcendental'. Mas a questão central é a seguinte: "poderemos hoje continuar a organizar a multiplicidade de acontecimentos que nos chegam do mundo, o humano e não-humano, colocando-os sob a Idéia de uma história universal da humanidade?"23.

J. F. Lyotard nos adverte que não tratará tal questão como filósofo, contudo, ela é merecedora de diversos esclarecimentos: no primeiro esclarecimento, fica evidente que poderemos continuar a organizar. A modernidade faz isso; a própria palavra modernidade não é uma época, mas um modo, de acordo com a origem latina da palavra. Na modernidade existe o esforço para controlar todos os dados, incluindo a si próprio, exemplo disso é o próprio Discurso de Descartes, é o gênero narrativo na primeira pessoa. J. F. Lyotard mostra que "este modo moderno da organização do tempo desenvolve-se no séc. XVIII na Aufklärung"24; nos séculos XIX e XX o pensamento e a ação são regidos pela ideia da emancipação. As grandes narrativas tentam ordenar os acontecimentos desde a narrativa cristã até a "narrativa capitalista da emancipação da pobreza pelo desenvolvimento tecnoindustrial"25. Há nessas narrativas disputas, mas, também, permanece a necessidade de liberdade universal.

No segundo esclarecimento, proposto por nosso autor, a respeito da questão inicial "'poderemos continuar a organizar etc?'", mesmo a resposta sendo negativa, ela não pode deixar de admitir a persistência do nós. Mas em que consiste o nós? É uma comunidade de sujeitos. Mas ele é independente "da Idéia de uma história da humanidade?"26, questiona J. F. Lyotard.

22. op. cit., p. 33-34.

23. op. cit., p. 37.

24. op. cit., p. 38.

25. op. cit., p. 38-39.

26. op. cit., p. 39. 
Na modernidade a emancipação consiste na terceira pessoa, que toma parte na comunidade dos locutores atuais. Contudo, a terceira pessoa será banida e o "nós" da questão colocada por J. F. Lyotard27 faz parte da tensão que a humanidade sentirá. Assim, é preciso rever o estatuto do "nós" que a pergunta impõe. É preciso repensar o projeto da humanidade livre. Nesse objeto perdido, o sujeito é conduzido a espécies de luto: o luto da unanimidade, que, anterior a este, foi o próprio luto de Deus que deu lugar ao modo moderno. Conforme J. F. Lyotard, outra maneira de fazer o luto da emancipação universal seria trabalhar a perda do sujeito prometido pelo projeto moderno.

O terceiro esclarecimento refere-se às palavras "poderemos nós?" da pergunta "poderemos nós hoje continuar a organizar os acontecimentos segundo a Ideia de uma história universal da humanidade?" 28 . E mais, temos força e competência para sustentarmos o projeto moderno? Questiona J. F. Lyotard. A discussão que se segue nos leva a pensar sobre o enfraquecimento do sujeito moderno. As grandes narrativas de emancipação foram invalidadas, refutadas, um exemplo disso J. F. Lyotard dá-nos a saber, a partir da seguinte afirmação de G. W. F. Hegel: "tudo o que é real é racional, tudo o que é racional é real" 29 . Ora, Auschwitz refuta completamente e inquestionavelmente tal doutrina. J. F. Lyotard apresenta uma série de acontecimentos que enfatizam o enfraquecimento da modernidade. Assim ele nos diz: "as grandes narrativas tornaram-se pouco credíveis. Nesse ponto, somos tentados a dar credibilidade à grande narrativa do declínio das grandes narrativas" ${ }^{\prime 30}$. J. F. Lyotard mostra, com isso, a fragilidade da própria crítica a respeito das grandes narrativas. O que está em causa na questão "podemos perpetuar as grandes narrativas?" 31 , não é se podemos, mas se devemos. "O que está em causa aqui é a contingência do encadeamento na situação que descrevi como enfraquecimento da modernidade" 32 . Uma delas já apresentamos, a falência da racionalidade diante do real de 'Auschwitz'. Logo, o poder tem a ver com o justo. É preciso dizer que ao que concerne ao encadeamento, diversas são as maneiras de fazê-lo, o que resta é decidir.

J. F. Lyotard completa:

toda política se contém na forma como se encadeia uma frase atual em outra frase. Não é uma questão de volume do discurso, nem de importância do locutor ou do destinatário. Nas outras frases, que atualmente são possíveis, uma será atualizada, e a pergunta atual é: qual? Para responder a esta pergunta, a descrição do enfraquecimento não nos fornece fio condutor. É por isso que sob o termo pós-modernidade as perspectivas mais contrárias podem achar-se reunidas. Limito-me a indicar, atra-

27. "Continuaremos a pensar e a agir a coberto da Idéia de uma história da humanidade?" (op. cit., p. 40).

28. op. cit., p. 41. 
vés destas observações, a direção antimitologizante na qual creio que deveríamos 'trabalhar' a perda do nós moderno ${ }^{33}$.

Ainda em Missiva sobre a história universal, são abordadas algumas outras questões: a questão da universalidade das grandes narrativas, em seguida o estatuto do nós, a razão do enfraquecimento da modernidade e a questão contemporânea de legitimação.

Ao entrarmos em uma cultura é preciso aprendermos os nomes, as unidades de medida, de espaço, de tempo e de valor de troca; são os chamados "designadores rígidos" 34 . Esses nomes são aprendidos, alojados em pequenas histórias e a vantagem da narrativa é admitir "uma multiplicidade de famílias heterogêneas de discurso" 35 . Nas sociedades 'selvagens', diz-nos J. F. Lyotard, "a forte coerência desta organização é duplicada pelo modo de transmissão da narrativa" 36 . Nessas sociedades, por exemplo, a sociedade dos Cashinahua, "a frase, legitimando o destinador que apresenta o seu universo, legitima-se a si própria junto do destinatário"37. E mais,"a narrativa e a sua transmissão fornecem de uma só vez à resistência a sua legitimidade" ${ }^{\prime \prime 8}$, que é asseverada pela potência do dispositivo narrativo, a narrativa, de acordo com J. F. Lyotard, "é a própria autoridade. Autoriza um nós infrangível, fora do qual não há nada a não ser eles"39.

A oposição desta conduta, ou modo de agir, é a das grandes narrativas de legitimação que caracterizam a modernidade ocidental. De acordo com I. Kant, segundo J. F. Lyotard, elas são cosmopolitas. Reportam-se "à 'superação' da identidade cultural específica no sentido de uma identidade cívica universal" ${ }^{\prime 4}$.

Onde se coloca o estatuto do nós?

J. F. Lyotard caminha para essa descrição apontando o fracasso do "nós, o povo francês" ${ }^{\prime 4}$. O exemplo escolhido por ele é o fracasso do movimento operário, o fracasso da ideia do trabalhador emancipado da condição proletária. Segue-se que "a multiplicação das lutas de independência desde a Segunda Guerra Mundial e o reconhecimento de novos nomes nacionais parecem indicar o reforço das legitimidades locais e a dissipação de um horizonte universal de

29. op. cit., p. 42.

30. op. cit., p. 43.

31. Ibid.

32. Ibidem.

33. op. cit., p. 43-44.

34. Ibid.

35. op. cit., p. 45 .

36. Ibid.

37. op. cit., p. 46 .

38. Ibid.

39. op. cit., p. 47.

40. Ibid.

41. op. cit., p. 48. 
emancipação" ${ }^{42}$. Depois da Segunda Guerra Mundial surgem os jogos de dominação do mercado, tais jogos agravam as desigualdades, as fronteiras não caem, servem, ao contrário, para fins especulativos e o "mercado mundial não faz uma história universal no sentido da modernidade. As diferenças culturais são além do mais encorajadas como mercadorias turísticas e culturais, a todos os níveis da gama" 43 .

Sobre isso, chamamos a atenção para a expansão do chamado multiculturalismo que vem sendo amplamente incentivado, não só por conta de uma tomada de consciência de que as diferenças, ao invés de engessarem a convivência humana, ao contrário, intensificam a compreensão da realidade, mas sim, porque tal incentivo significa um controle social mediado pelo mercado. Essa questão tem a ver, acreditamos, com o apaziguamento da sociedade civil. A estratégia comporta o esvaziamento das diferenças, reduzindo-as à mera diversidade cultural, ou a meras singularidades.

Prosseguindo com nossa discussão, J. F. Lyotard questiona: "qual é, finalmente, o nós que tenta pensar esta situação de enfraquecimento? Os intelectuais? Eles estarão sempre entrando em confronto com este enfraquecimento. A contundência do discurso de J. F. Lyotard surge ao afirmar o seguinte:

mas a violência da crítica oposta à escola nos anos sessenta, seguida pela degradação inexorável das instituições de ensino de todos os países modernos, mostra suficientemente que o saber e a sua transmissão deixaram de exercer autoridade que fazia com que ouvíssemos os intelectuais quando eles passavam da cátedra à tribuna. Num universo em que ter sucesso é ganhar tempo, pensar tem apenas um defeito, mas esse é incorrigível: faz perder tempo ${ }^{44}$.

J. F. Lyotard não pretende dar respostas às questões anteriores a esta citação, mas pô-las em debate; todavia, é enfático ao afirmar que é preciso traçar "uma linha de resistência ao enfraquecimento moderno" ${ }^{\prime 4}$.

Em Memorando Sobre A Legitimidade, J. F. Lyotard aborda a questão do totalitarismo do ponto de vista da linguagem da legitimação que, segundo ele, é mais radical do que qualquer outra, pois realiza-se "sem recorrer a entidades, que frequentemente não interrogamos por negligência, como poder, sociedade, povo, tradição, etc" 46 .

Quanto a isso, J. F. Lyotard recorre a algumas exposições para nos demonstrar a questão do totalitarismo: uma delas diz respeito à distinção feita por I. Kant

\footnotetext{
42. Ibid.

43. op. cit., p. 49.

44. Ibid.

45. op. cit., p. 50.

46. op. cit., p. 53.
} 
quanto à política da Aufklärung crítica, no Projeto de Paz Perpétua. Segundo J. F. Lyotard, a questão da legitimação não é diretamente tratada na segunda seção, primeiro artigo, contudo, ele gostaria de discutir a distinção dos regimes, despótico e republicano, para tanto, é preciso colocar em questão a instância de legitimação ao sujeito da frase normativa "frase que tendo por objeto uma frase prescritiva Ihe dá a força de lei" 47 . Em resumo: "a autorização autoriza a autoridade, ou seja: é a frase normativa que autoriza $Y$ [instância que legitima a prescrição dirigida a X] a normatizar"48.

Refletindo sobre o totalitarismo, J. F. Lyotard diz que, as narrações, tanto as míticas quanto às metanarrativas ou narrativas de emancipação, são processos de linguagem que marcaram um círculo vicioso bastante conhecido: $Y$ tem autoridade sobre $X$, porque $X$ autoriza $Y$ a tê-la: criam-se, portanto, as petições de princípio, ou seja, as conclusões já estão inseridas nas premissas.

Para esclarecer o funcionamento do exposto acima, J. F. Lyotard passa a tratar daquilo que sustenta seu discurso: a linguagem. Ela "é o objeto de uma Ideia" ${ }^{49}$, e não um armazém de artigos. O que existem são frases que exprimem significações e situam um destinador, um destinatário e um referente. Assim, essas frases serão ou descritivas, ou prescritivas, ou narrativas, ou interrogativas etc.

Há ainda um outro aspecto que ordena a argumentação de J. F. Lyotard a respeito do totalitarismo, a saber: cada frase chega como um acontecimento não no sentido de uma excepcionalidade, mas no sentido de que ela "nunca é necessária no seu conteúdo" ${ }^{50}$. Ora, precisamos entender isso. Conforme J. F. Lyotard,

é necessário que algo aconteça, a ocorrência, mas aquilo que acontece (a frase, o seu sentido, o seu objeto, os seus interlocutores) nunca é necessário. Necessidade da contingência ou, se preferires, ser do não ser. Entre uma frase e uma frase, o encadeamento em princípio não é pré-determinado ${ }^{51}$.

Os gêneros de discurso existem, cada um deles, com seu fim, por exemplo, convencer. As regras são respeitadas e promovem o encadeamento das frases, mas, segundo J. F. Lyotard, essas regras só são respeitadas na poética e na retórica clássicas. As infrações a essas regras passam a ser cometidas pelos escritores e artistas modernos, pois o valor não está na conformidade com as regras, mas no acontecimento.

47. op. cit., p. 54 .

48. Ibid.

49. op. cit., p. 55.

50. op. cit., p. 56

51. Ibid. 
J. F. Lyotard retoma a reflexão sobre a narrativa de legitimação e o totalitarismo primeiro, a partir da narração mítica, cuja importância está não na análise dos conteúdos narrativos, mas sim, na pragmática da narração. Cita o exemplo dos Cashinahua para mostrar que a transmissão narrativa obedece obrigações e destinações a respeito daquele que ouve, daquele que conta e daquele que é objeto da narrativa, portanto, a pragmática narrativa impõe regras de autenticação e de conservação da comunidade a partir da repetição dos nomes. Este dispositivo de linguagem, que contempla três instâncias narrativas, (o narrador, o ouvinte e o herói) é, segundo J. F. Lyotard, exemplar para o regime que I. Kant chamava de despótico e, portanto, "para a legitimação da instância normativa que Ihe corresponde" 52 . Essas narrativas ordenam, transmitem tradições, legislam. Há uma política nesta prática narrativa e, por isso, J. F. Lyotard a considera "totalitária" 53. A narrativa como legitimação conduz-nos a pensar no totalitarismo moderno, o exemplo imediato a que recorre J. F. Lyotard é o Nazismo.

Continuando a abordagem do totalitarismo e tomando como via de compreensão aquela que o permite falar da linguagem da legitimação, J. F. Lyotard prossegue para o aspecto que engloba a questão do republicanismo onde há, segundo ele, a fragmentação da identidade popular. Do ponto de vista da linguagem, ela organiza regimes de frases e gêneros de discurso que repousam sobre "a sua dissociação e que por isso deixa entre eles "jogo", ou, se preferirmos, que preserva a possibilidade de que o acontecimento na sua contingência seja levado em consideração" ${ }^{\prime 54}$.

Esta organização é chamada de deliberativa, ela é própria da política, e tem por características as seguintes: o fim superior é formulado através de uma frase canônica, ou seja, é uma prescritiva interrogativa; as respostas são dadas pelas filosofias da história, pouco debatidas, mas presentes. Depois, passa-se da prescrição para um imperativo hipotético e, para isso, recorre-se ao gênero dos especialistas, em seguida, são montados cenários ou simulações, só então, surge o regime da argumentação que Aristóteles chamava dialética. Chega-se ao momento da decisão, do escrutínio, da legitimação, em seguida ao normativo, e, finalmente, ao executório e as infrações punidas. Por conta dessa heterogeneidade, há uma espécie de fragilidade do discurso deliberativo, agravada pela deliberação constante dos cientistas. Segundo J. F. Lyotard, não há certeza na república, pois há incerteza sobre a identidade do 'nós'. Por isso há várias narrativas.

Diante disso, se quisermos uma definição a respeito da modernidade, J. F. Lyotard nos diz claramente que:

As grandes narrativas que existem são narrativas de emancipação, não são mitos. Preenchem, como eles, uma função de legitimação, legitimam

52. op. cit., p. 58.

53. op. cit., p. 59.

54. op. cit., p. 60. 
instituições e práticas sociais e políticas, legislações, éticas, maneiras de pensar simbólicas. Diversamente dos mitos, não encontram, no entanto, essa legitimidade em actos originais "fundadores", mas num futuro a fazer advir, ou seja, numa Idéia a realizar. Essa Idéia (de liberdade, de "luz", de socialismo, de enriquecimento geral) tem um valor legitimante porque é universal. Dá à modernidade o seu modo característico: o projecto, ou seja, a vontade orientada para um objetivo ${ }^{55}$.

Essa vontade, orientada para um objetivo, poderia ser compreendida ao pensarmos na questão: O que são as Luzes? Mas, de acordo com J. F. Lyotard, isso não pôde ser feito neste escrito. $O$ que interessa afirmar aqui é que a narrativa da história universal da humanidade passa, invariavelmente, pela discussão desta história que é dialética "no sentido kantiano, ou seja, sem conclusão"56.

A legitimidade é extraída de uma comunidade, esta é a única coisa certa, a sociedade real precisa da comunidade para isso. Poderíamos acrescentar que um exemplo disso, atualmente, é o surgimento de diversas comunidades religiosas que, adquirem sua legitimidade diante da sociedade soberana, da qual elas fazem parte, exatamente por se constituírem enquanto comunidades. $\mathrm{Na}$ sociedade soberana, estabelecida nos Estados-Nações, "A soberania não é o povo, mas a Ideia da comunidade livre. E a história só aí está para marcar a tensão desta falta. A república invoca a liberdade contra a segurança" ${ }^{\prime \prime}$.

J. F. Lyotard afirma que diante do exposto, fica mais fácil saber o que vem a ser o totalitarismo. Há a diferença daquele que não se manifesta a respeito da legitimação moderna pela Ideia de liberdade, e aquele que, ao contrário, é produto disso. Quando, por exemplo, fecha-se os olhos para a Declaração dos Direitos de 1789, isso não caracteriza "um 'abandono' do projeto moderno, como diz J. Habermas a propósito da pós-modernidade, mas sua 'liquidação'" 58 . Pode-se suspeitar que a história universal não conduz seguramente "para o melhor 'como' dizia I. Kant, ou, antes, que a história não tem necessariamente uma finalidade universal" 59 .

Ainda partindo do texto da Declaração do Direitos do Homem, especificamente no Preâmbulo, é possível observar a relação da autoridade na tradição e da autoridade na Ideia. A instância legitimadora é a Assembleia, uma instância singular. Surge daí uma questão ímpar: "como saber, depois, se as guerras conduzidas pela instância singular em nome da instância universal são guerras de libertação ou de conquista?"60.

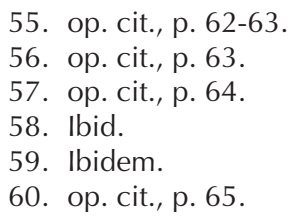


Face ao nazismo, a organização deliberativa tem as mesmas características, e o núcleo deste equívoco está na ideia de povo, o nazismo soube valorizá-lo. De acordo com J. F. Lyotard,

As 'festas' nazis, monumentais ou familiares, exaltam a identidade germânica tornando sensíveis aos olhos e aos ouvidos as figuras simbólicas da mitologia ariana. Trata-se de uma arte da persuasão, que só conseguiu lugar eliminando as correntes vanguardistas orientadas para a reflexão ${ }^{61}$.

Ainda segundo J. F. Lyotard, citando G. W. F. Hegel, o ideal de liberdade absoluta é vazio e conduz ao Terror. De acordo com J. F. Lyotard,

a única instância normativa, a única fonte de lei, o único $Y$, é a pura vontade, que nunca é isto ou aquilo, nunca é determinada, é apenas potência de ser tudo. Por isso julgar que qualquer acto singular, mesmo prescrito pela lei, executada dentro de regras, não está à altura do ideal. O Terror realiza a suspeita de que ninguém é suficientemente emancipado. Transforma-a em política. Qualquer realidade singular conspira contra a vontade pura universal62.

A citação acima nos oferece elementos bastante importantes, não só para o confronto ou paralelo daquilo que chamamos de modernidade e pós-modernidade, mas também, nos dá o alcance e o limite, ou pelo menos a origem da repulsa daquilo que vem sendo chamado de pós-modernismo.

Quanto ao potencial do Terror, o que há de significativo sobre isso é que ele esbarra no acontecimento, ou intensifica o seu insucesso, já que a organização deliberativa abre espaço para o encadeamento tanto das frases como dos gêneros de discurso e, tanto um como o outro, fazem parte do processo da vontade. A república, de acordo com J. F. Lyotard, "é por constituição atenta ao aconte-

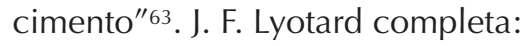

o terror é uma forma de levar em consideração a indeterminação do que acontece. A filosofia é outra forma. A diferença entre estas duas formas reside no tempo disponível para acolher e para julgar. A filosofia dá a si própria tempo, como se diz. A urgência apressa a decisão republicana, política, em geral ${ }^{64}$.

Por que, então, para J. F. Lyotard, o totalitarismo é moderno?

61. op. cit., p. 66.

62. op. cit., p. 67.

63. op. cit., p. 68.

64. Ibid. 
No caso do nazismo, "o 'nós' singular, nomeado, eleva a sua pretensão a dar o seu nome ao objetivo que a história humana persegue" ${ }^{\prime 65}$. Quanto ao capitalismo, J. F. Lyotard afirma que o totalitarismo que aí reside não o habita no sentido político, mas apela para a

hegemonia completa do gênero de discurso econômico. A fórmula canônica simples deste último é: Cedo-te isto, se puderes contracederme aquilo. E este gênero tem a propriedade, entre outras, de apelar sempre a novos, isto para entrarem na troca (por exemplo hoje os acontecimentos tecnocientíficos) e de neutralizar o seu poder de acontecimento através da sua liquidação ${ }^{66}$

O capital, segundo J. F. Lyotard, não necessita nem politicamente, nem economicamente da deliberação. Ele necessita de uma sociedade que consuma. Ele não precisa de legitimação, está presente em toda parte mais como necessidade do que como finalidade e esta significa ganhar tempo.

As discussões aqui expostas nos reportam àquela produzida por J. F. Lyotard no décimo capítulo d'A condição pós-moderna, principalmente quanto ao uso que se tem feito dos conhecimentos tecnocientíficos. A apreensão de tais conhecimentos é estimulada não porque isso significará uma melhoria de vida para aqueles que se submetam a ela, mas por que induzir e facilitar uma dependência desses meios, garante uma reprodução acrítica dos instrumentos que compõem os mecanismos de controle da sociedade civil. É por isso que Roberval de Jesus Leoni dos Santos nos diz:

a sociedade civil, ao controlar-se a si mesma, dispensa, naturalmente, qualquer expertise, porque ela própria, aí, é a superação de suas amarras em torno dos transtornos do passado. Não há necessidade de se conhecer os dados coligidos e nem de processá-los em um universo metodológico - portanto, não há necessidade de conhecimentos substanciais acerca do passado, porque tudo isso já está circunscrito a uma lógica préestabelecida, capaz de readaptar-se a qualquer momento, desde que se Ihe reprograme as determinações. O papel da informática nisso, portanto, é essencial ${ }^{67}$.

A quinta carta, desta sequência de escritos que compõem o livro O pós-moderno explicado às crianças, é Telegrama A Propósito Da Confusão Das Razões. De que confusão das razões J. F. Lyotard trata? Segundo ele, "o termo razão é muito vasto" 68 , limitando sua extensão, ele aceita dizer que razão, tal como nos

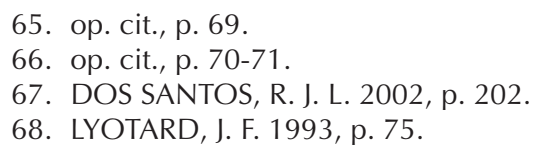


chegou desde G. Galileu, pode ser compreendida como "conjunto de regras que um discurso deve respeitar se visa reconhecer e fazer conhecer um objeto" 69 . Segundo J. F. Lyotard, não há uma mudança considerável das regras do discurso científico hoje, comparadas às de outrora, elas apenas se constituíram mais explícitas. Podemos afirmar, portanto, que não há ruptura, por exemplo, quanto ao discurso da ciência na modernidade e na pós-modernidade.

A questão central neste escrito é falar do discurso científico, e a diferença que há entre ele e os outros gêneros de discurso. Quando estes o tomam por objeto, a ideia de razão científica se ideologiza. A questão defendida por J. F. Lyotard é a de que a razão científica não é independente de variáveis empíricas (técnicas, sociais, psíquicas, imaginárias), ao contrário, elas afetam o seu conteúdo mais do que o seu regime. A hipótese de J. F. Lyotard é a seguinte: "a razão cognitiva reside nas regras do jogo da linguagem"70. Questão largamente discutida em A condição pós-moderna. Diante disso, J. F. Lyotard propõe que a discussão se encaminhe para a questão do estatuto das regras do jogo.

A razão científica nos induz a um sentimento de uma maior incerteza? Qual a origem das regras do conhecimento? Qual é a razão da razão? Em última instância, essa é a questão que envolve um grande debate que J. F. Lyotard brevemente percorre. Segundo ele, "o classicismo era metafísico"71. Na modernidade, em particular aquela ditada por S. Agostinho e I. Kant, a razão é crítica, mas o fundamento do raciocínio é proibido pela razão. Na pós-modernidade ela é empírico-crítica ou pragmatista"72. Aqui, o que conta é a necessidade das regras existirem. Mas, o que prevalece para J. F. Lyotard é que "a ciência seria um meio de revelar a razão, permanecendo esta a razão de ser da ciência"73. O questionamento em torno da ciência refere-se à sua performatividade e não segundo o critério do verdadeiro ou do falso. Segue-se que, quanto mais equipamento tiver um laboratório, as hipóteses de ter razão serão melhores.

Será a razão do mais forte a razão verdadeira? pergunta J. F. Lyotard. Para ele, a tecnociência é um estado de razão. Uma razão ditada, ou pelo menos determinada, pelo capital mercantil. É o regime do mais performativo. Existe uma ruína da profissão cognitiva? Admitindo a analogia do desaparecimento do tecelão, posto em seu lugar o modo de produção fabril; o que restaria? J. F. Lyotard responde: "restaria que o ofício de conhecer não teria hoje em si mesmo mais a sua legitimidade, a sua razão e o seu fim do que o de fabricar têxtil sintético"74.

69. Ibid.

70. op. cit., p. 76.

71. op. cit., p. 77.

72. Ibid.

73. Ibidem.

74. op. cit., p. 78. 
No caso do saber pertencer aos poderes públicos, só a estes poderes ele deveria dar respostas. Nos dois casos, a razão da razão cognitiva inseri-se na ordem social, econômica e política. $\mathrm{O}$ crédito às grandes narrativas de emancipação justifica-se através disso. Separar ciência do Estado como pede P. Feyerabend, põe em discussão a confusão das razões "a razão do Estado e a razão de saber"75. Esta confusão relaciona-se com o projeto, segundo J. F. Lyotard, muito moderno de uma metalinguagem. A dúvida da razão surge "da crítica da metalinguagem, ou seja, do declínio da metafísica"76. Tudo isso é indicativo, segundo J. F. Lyotard, do que está em jogo no pensamento filosófico hoje, ou seja, resistir ao pragmatismo positivista e ao dogmatismo.

Contra argumentando a acusação feita por G. Raulet de que seu pós-modernismo seria tão impotente diante do totalitarismo, "como o foi o vanguardismo de Weimar face ao nazismo crescente" 77, J. F. Lyotard constrói três argumentos: em primeiro lugar, aproximar o termo totalitarismo do nazismo e do capitalismo, na sua face pós-moderna, é superficial. Os dois se apoderam da totalidade da vida de maneiras diferentes. O primeiro buscando, a partir da vontade, legitimidade, e o outro, tendo em vista o mercado sem preocupações com a legitimação. Neste caso, o vanguardismo não tem, segundo J. F. Lyotard, o mesmo alcance. $\mathrm{O}$ nazismo assassina e o capitalismo isola as vanguardas.

Em segundo lugar, quanto a impotência de "seu" pós-modernismo, J. F. Lyotard interessa-se em afirmar que o declínio dos ideais modernos trouxe com ele uma falência dos intelectuais. Na pós-modernidade estão inscritos esses erros. São as vanguardas que têm salvado o pensamento. Em último lugar, J. F. Lyotard diz que sua luta foi "contra a pseudo-racionalidade imposta pelo capitalismo, contra a performatividade" ${ }^{\prime 78}$. Neste sentido, diz-se fiel à dialética aristotélica e a I. Kant. A confusão reinante instaura-se quando a "Razão" é invocada. Para J. F. Lyotard, é preciso dissociar a razão em três tipos: a razão dos fenômenos, que pode legitimar um regime político; a razão que faz com que cada um suporte sua singularidade e nos permite admirar uma obra e "a razão pela qual há um dever, ou uma dúvida"79. É o racionalismo crítico que promove essas dissociações e permite resistir ao totalitarismo presente.

Em Nota sobre os sentidos de 'pós' J. F. Lyotard propõe observações que destacam alguns problemas relacionados com o termo "pós-moderno". A intenção não é, segundo o autor, resolvê-los, fechar o debate, mas procurar "evitar confusões e ambiguidades" 80 . Para tanto, estabelece três pontos, os quais exporemos a partir de agora.

75. Ibid.

76. op. cit., p. 80.

77. LYOTARD, J. F. 1993, p. 87.

78. op. cit., p. 88.

79. op. cit., p. 88-89.

80. op. cit., p. 93. 
O primeiro ponto destacado por J. F. Lyotard diz respeito à oposição entre o pós-modernismo e o modernismo, ou o Movimento Moderno (1910-1945), em arquitetura. A primeira conotação do termo "pós-moderno" passa pela noção de ruptura tomada de Portoghesi. Segundo ele, esta ruptura diz respeito à "revogação da hegemonia concedida à geometria euclidiana tal como foi sublimada, por exemplo, na poética plástica do "Stijl".

Já para Gregotti, segundo J. F. Lyotard, a diferença modernismo/pós-modernismo caracteriza-se "pelo desaparecimento da íntima relação que associava o projeto arquitetural moderno com a idéia de uma realização progressiva da emancipação social e individual à escala da humanidade" ${ }^{\prime 2}$. A noção de emancipação ou o horizonte de universalidade não faz parte dos projetos do arquiteto, o que há é uma "bricolage". J. F. Lyotard considera o "pós-modernismo" como "uma simples sucessão, de uma sequência diacrônica de períodos em que cada um é, em si mesmo, claramente identificável. "O 'pós' indica algo como uma conversão: uma nova direção depois da anterior" 82 . De acordo com J. F. Lyotard, a ideia de linearidade é moderna e a modernidade correlaciona-se com a possibilidade e necessidade de rompimento com a tradição para instaurar uma maneira de viver e de pensar absolutamente nova. A explicação a respeito do 'pós' e a respeito da necessidade do novo, poder parecer, não acrescentar quase nada ao debate pós-moderno. Contudo, aquilo que J. F. Lyotard pondera, não como uma simples sucessão, mas sim uma nova direção depois da anterior, nada mais reflete do que o próprio movimento da história, portanto, é possível percebermos que a noção de uma ruptura entre modernidade e pós-modernidade não se adequa ao que de fato ocorre. Diante do que J. F. Lyotard expõe, o que se mostra mais factível é conduzirmos nossa compreensão dessa condição, que se apresenta nos dias de hoje, a partir de uma noção de re-arranjo entre aquilo que era prioridade para a modernidade e o que é para a pós-modernidade.

Finalizando o primeiro ponto acerca do pós-moderno, J. F. Lyotard diz supeitar de que a 'ruptura', palavra aspejada pelo autor, é, antes de tudo, "uma maneira de esquecer ou de reprimir o passado, ou seja, de o repetir, mais do que de o ultrapassar" 83 (grifos nossos). Assim, tanto na arquitetura como na pintura, o que prevalece nas correntes vanguardistas ou neo-expressionistas é a repetição e/ou a citação.

A segunda conotação do termo "pós-moderno" está filiada à desconfiança do princípio do progresso geral da humanidade. A ideia de progresso estava ligada à certeza de que o desenvolvimento do conhecimento resultaria no desenvolvimento da humanidade. Contudo, quem era a vítima da falta de desenvolvimento? O pobre? O trabalhador? O iletrado?

81. Ibid.

82. op. cit., p. 94.

83. Ibid. 
As controvérsias foram inúmeras, mas ao longo dos séculos XIX e XX, as tendências que se opunham, assemelhavam-se quanto à firme convicção de que a legitimidade das descobertas e instituições seria gerada ao tempo que estas e aquelas contribuíssem para a emancipação da humanidade. Todavia, depois destes séculos, XIX e XX, um movimento contrário a todas essas expectativas surge, pois os signos que as repudiam tornam-se, por conta de nossa atenção, mais evidentes. Segundo J. F. Lyotard, Auschwitz é um exemplo incontestável, sugerindo, portanto, que o pensamento que reabilitou atitudes tão reacionárias não trouxe a tão aclamada emancipação universal.

J. F. Lyotard amplia as dúvidas a respeito desta emancipação e afirma que longe de trazer progresso, as tecnociências aumentaram o mal-estar. Qual é a razão deste progresso de complexificação? questiona J. F. Lyotard. Para ele, as necessidades imediatas humanas, como por exemplo, a felicidade, não têm pertinência alguma para o progresso, cuja preocupação é numerizar. Quanto a isso, J. F. Lyotard afirma:

Estamos no mundo tecnocientífico como se fôssemos Gulliver, umas vezes demasiado grandes, outras demasiado pequenos, nunca numa escala apropriada. Nesta perspectiva, a exigência de simplicidade surge em geral, hoje, como uma promessa de barbárie.

Seria preciso, mesmo relativamente a este ponto, elaborar a questão seguinte: a humanidade divide-se em duas partes. Uma defronta o desafio da complexidade, a outra o antigo, terrível desafio da sua sobrevivência. É talvez o principal aspecto do fracasso do projeto moderno, do qual te recordo que era em princípio válido para a humanidade no seu conjunto ${ }^{84}$.

Quanto ao que acabamos de citar, perguntamos: o que seria uma escala apropriada no mundo tecnocientífico? Quem a determinaria? Quais seriam os critérios para isso? J. F. Lyotard não responde a essas questões e passa para o terceiro ponto. Embora mais complexo, segundo ele, mais abreviada foi sua reflexão sobre ele.

As expressões do pensamento artístico, literário, filosófico e político condensam a questão da pós-modernidade. Do ponto de vista das artes visuais ou plásticas há uma ideia dominante, segundo J. F. Lyotard, de que, hoje, as vanguardas acabaram, pois expressavam uma modernidade ultrapassada. Mas, segundo nosso autor, "o verdadeiro processo de vanguardismo foi na realidade uma espécie de trabalho, longo, obstinado, altamente responsável, orientado para a procura das pressuposições implicadas na modernidade" 85 . Ou seja, compreender a obra dos pintores modernos, significa compará-la "com uma anam-

84. op. cit., p. 96-97.

85. op. cit., p. 97. 
nese no sentido da terapêutica psicanalítica" ${ }^{\prime 86}$. Ao abandonarmos isso, corremos o risco de repetir a "neurose moderna", geradora das infelicidades conhecidas durante dois séculos.

J. F. Lyotard finaliza esta carta alertando que o " 'pós', do 'pós-moderno', não significa um movimento (...) de repetição, mas um processo em 'ana', um processo de análise, de anamnese, de anagonia, e de anamorfose, que elabora um 'esquecimento inicial" 87.

Em Bilhete para um novo cenário, o vigor da crítica ao "projeto moderno" aparece de maneira contundente. J. F. Lyotard retoma a discussão acerca do surgimento da Aufklärung no final do séc. XVIII, as ações e pensamentos dela decorrentes até o séc. XX. Segundo ele, na filosofia das Luzes havia a promessa da liberdade para todos, logo, a emancipação da humanidade. As correntes políticas, excetuando-se, principalmente, o nazismo, tiveram por princípio levar a uma cidadania mundial. Contudo, para os países desenvolvidos, tais ideais estão em declínio. O desenvolvimento tecnocientífico (artístico, econômico e político) possibilitou, dentre tantas coisas, os totalitarismos, a pobreza "a desculturação geral com a crise da escola, ou seja, da transmissão do saber, e o isolamento das vanguardas artísticas (e agora, durante algum tempo, a sua renegação)" ${ }^{\prime \prime 8}$.

Os interditos a favor do "projeto moderno" existem. Um deles é o silêncio sobre o nazismo na Alemanha. De acordo com J. F. Lyotard:

Este interdito, oposto à anamnese, vale como símbolo para todo o Ocidente. Poderá haver progresso sem anamnese? A anamnese conduz, através de uma dolorosa elaboração, a elaborar o luto das fixações, das afeições de todos os gêneros, amores e terrores, que estão associadas a estes nomes ${ }^{89}$.

Quanto ao declínio do "projeto moderno", J. F. Lyotard afirma que tal declínio não significa decadência, já que ele é acompanhado pelo desenvolvimento vertiginoso da tecnociência. O fato é que a ciência nunca esteve a favor das necessidades humanas, "daquilo que os homens podem pensar que é desejável, proveitoso, confortável. É que o desejo de saber-fazer e de saber é incomensurável relativamente ao benefício que se pode esperar do seu crescimento" ${ }^{\prime \prime}$.

Diante disso, três fatos chamam a atenção de J. F. Lyotard: "a fusão das técnicas e das ciências do enorme aparelho tecnocientífico; a revisão em todas as

\footnotetext{
86. Ibid.

87. op. cit., p. 98.

88. op. cit., p. 102.

89. Ibid.

90. op. cit., p. 103.
} 
ciências"91, principalmente dos modos de raciocínio e, por fim, "a transformação qualitativa que é o contributo das novas tecnologias" ${ }^{\prime \prime 2}$.

Paralelo ao processo de complexidade da ciência, está inscrito aquele realizado pelas vanguardas artísticas há mais de um século. Este processo direcionase às sensibilidades e não aos "saber-fazer" ou aos saberes. A complexidade não está restrita a um domínio, mas a maior parte deles, incluindo a vida cotidiana. É preciso tornar a humanidade apta a adaptar-se àquilo que excede ao que ela procura. A simplificação torna-se, portanto, o ponto nevrálgico dessa adaptação. Em decorrência disso, um novo cenário está sendo instalado, sob o critério do subdesenvolvimento. Esse subdesenvolvimento, acreditamos, passa também pelo totalitarismo que torna-se pleno quando elimina a contingência da escrita, o acontecimento. Um exemplo disso está em Glosa sobre a resistência. Nesta carta J. F. Lyotard análisa os comentários de Claude Léfort, a respeito do livro de G. Orwell, 1984.

O que prevalece em sua análise é a crítica aos totalitarismos, assim como o faz G. Orwell ao denunciar a via de controle utilizada no romance, a Novilíngua. No caso do totalitarismo real, suas bases não são políticas, mas econômicas e mass-midiáticas. No caso da Novilíngua, ela, além de renunciar aos poderes da linguagem, anula o acontecimento. Assim como a Novilíngua não têm espaço para os idiomas, a imprensa e a mídia não tem para a escrita. "À medida que a Novilíngua se expande, a cultura declina. O basic language é a língua da rendição e do esquecimento" ${ }^{\prime \prime 93}$. No romance de G. Orwell, segundo J. F. Lyotard, o despotismo não só tortura a necessidade como seduz o desejo. Hoje, esta tortura dá-se na medida em que, o que podemos observar é uma generalização, segundo J. F. Lyotard, das linguagens binárias. De acordo com nosso autor, esse totalitarismo culmina

No apagamento da diferença entre aqui-agora e ali-então, que resulta da extensão das tele-relações, no esquecimento dos sentimentos em benefício das estratégias, concomitantes à hegemonia do comércio, concluiremos que as ameaças que pesam por causa desta situação, a nossa, sobre a escrita, sobre o amor, sobre a singularidade, são, na sua natureza profunda, parentes das que foram descritas por Orwell ${ }^{94}$.

A ameaça é real e análoga àquela descrita por Orwell. O impacto das democracias midiáticas, das tecnociências, da competição econômica e militar mundial demonstram, em grande parte, o declínio dos ideais modernos. A pro-

91. Ibid.

92. Ibidem.

93. op. cit., p. 113.

94. op. cit., p. 114. 
messa de emancipação da humanidade não foi cumprida. De acordo com J. F. Lyotard,

é o próprio desenvolvimento que impede de a cumprir. O neo-analfabetismo, o empobrecimento dos povos do Sul e do Terceiro Mundo, o desemprego, o despotismo da opinião e portanto dos preconceitos repercutidos pelos media, a lei de que é bom o que é 'performativo' - isto não é devido à falta de desenvolvimento, mas ao desenvolvimento. É por isso que já não ousamos chamar-Ihe progresso ${ }^{95}$.

E continua:

uma guerra de libertação não anuncia que a humanidade continua a emancipar-se; nem a abertura de um novo mercado, que ela se enriquece, e a escola já não forma cidadãos, pelo menos profissionais. Qual é a legitimação que nós, portanto, temos a fornecer para a prossecução do desenvolvimento? 96

Desse ponto de vista, que tipo de resistência é traçada pelo romance de G. Orwell e pela arte? J. F. Lyotard responde que não serve para acalmar, mas para testemunhar e salvar a honra. Segundo ele, "o trabalho de escrever tem um parentesco com o trabalho do amor, mas inscreve a marca do acontecimento iniciático na linguagem, e oferece-o assim à partilha, se não à partilha do conhecimento, pelo menos à de uma sensibilidade que pode e deve considerar comum" $" 97$.

Há dúvidas, no entanto, quanto ao alcance da resistência produzida tanto pela escrita como pela arte, segundo J. F. Lyotard, "temos disso uma quantidade de sinais negativos"98, J. F. Lyotard refere-se à chamada 'superação' do vanguardismo e ao desprezo pela responsabilidade de resistir e de testemunhar assumida pelas vanguardas. Mas, mesmo mergulhado num claro pessimismo, recorda-nos que não devemos nos fechar em torres de marfim ou voltarmos as costas aos novos meios de expressão produzidos pelas ciências e técnicas contemporâneas, mas, ao contrário, fazer uso deles para continuar a resistência.

Similar à preocupação que desencadeia o romance de G. Orwell, o totalitarismo, Ira Lewin discute este mesmo tema no livro This Perfect Day (Este Mundo Perfeito), nele o autor inventa um mundo futuro, no qual a ação se passa 150 anos depois da unificação de todos os países. O herói, um rapaz apelidado de Quem, trava uma luta desesperada para encontrar liberdade na terra entorpecida por produtos psico-químicos e computadores. Seu avó, o Pai Jan, é o pri-

95. op. cit., p. 114-115.

96. op. cit., p. 115.

97. op. cit., p. 116.

98. Ibid. 
meiro a Ihe despertar a sensação de individualidade latente. Além dele, outras personagens figuram no romance: Karl, Lilás, Rei e Julia. A história se desenrola em várias décadas e continentes mostrando os triunfos e derrotas de Quem, para, finalmente, desencadear na destruição do super-computador 'Unicomp'. Na literatura e no cinema não são poucos os exemplos aos quais podemos recorrer para principiarmos uma discussão sobre os totalitarismos.

Na última carta, Mensagem a propósito do curso filosófico, J. F. Lyotard nos oferece, num primeiro momento, uma reflexão sobre a formação filosófica dos professores. De acordo com ele, a filosofia "não é uma entidade, uma potência, um 'corpo' de saber, de saber-fazer, de saber sentir, mas que existe apenas em ato" ${ }^{\prime 99}$. Nosso autor lembrar-nos dos Pré-socráticos até Platão para considerar que, diante daquilo que se pode entender por formação, é preciso compreendermos que seu núcleo essencial é a reflexão filosófica e o pressuposto fundamental é que "o espírito dos homens não lhes é dado como é preciso, e deve ser re-formado"100. Mas como o mestre se emancipa de sua monstruosidade infantil? Questiona J. F. Lyotard. Para ele, os filósofos têm muitos pais "para admitir uma paternidade. Em contrapartida, filosofar é antes de mais nada uma autodidática"101.

J. F. Lyotard entende o curso filosófico a partir da noção de que é preciso recomeçar, não do ponto de vista genealógico, mas retomar "uma qualquer questão, ou qualquer 'tema'"102. Portanto, "começa-se sempre pelo meio. É por isso que o projeto de um curso filosófico, projeto que vem das ciências exatas, parece votado ao fracasso" 103 .

E o que significa ser autodidata? Não significa que não se aprende nada com os outros, significa, tão-somente, que é preciso desaprender. Neste processo, a leitura filosófica só é filosófica se for autodidática, ou seja, "se for um exercício de desconsertação relativamente ao texto, um exercício de paciência. (...) É um exercício de escuta"104. Neste exercício é preciso reexaminar os pressupostos, os subtentidos, consiste na anamnese, a saber, "na procura daquilo que permanece impensado quando já está pensado"105.

J. F. Lyotard compreende que o curso filosófico trabalha a realidade afastandose, principalmente, de um dos seus critérios que é 'ganhar tempo'. Essa é a grande dificuldade do professor de Filosofia, fugir dos valores imperativos do desenvolvimento, da 'performance', da velocidade, do contrato. Resgatando I.

\footnotetext{
99. op. cit., p. 119.

100. Ibid.

101. op. cit., p. 120.

102. Ibid.

103. Ibidem.

104. op. cit., p. 121.

105. Ibid.
} 
Kant, J. F. Lyotard nos lembra: "não se ensina filosofia, ensina-se, na melhor hipótese, simplesmente a filosofar"106. E continua, "é preciso filosofar para ensinar a filosofar" 107 .

O segundo momento da carta diz respeito a uma distinção elaborada por I. Kant e recuperada por J. F. Lyotard acerca da filosofia. Para o filósofo de Königsberg haveria um conceito escolar de filosofia e um outro mundano. Aquele é um exercício dialético, tanto em I. Kant quanto em Aristóteles. O mundano diz respeito a reconduzir os conhecimentos às finalidades essenciais da razão humana. A razão da filosofia no mundo acrescenta um interesse prático e, para I. Kant, os interesses são contraditórios. Segue-se disso a questão levantada por J. F. Lyotard, "o professor de Filosofia hoje terá mais a ver com a escola ou com o mundo?"108.

É factível compreender que as mesmas urgências que acometem o mundo também dizem respeito à escola, pois ela não está isolada, à parte do mundo, portanto, ao pensar o mundo ou a escola, o professor de filosofia pode elaborar aquele trabalho de resistência mencionado por J. F. Lyotard. Segundo ele, I. Kant e, mais especificamente a modernidade, puseram a escola no centro do interesse popular e prático da razão, cujo objetivo era formar o cidadão na república. Filosofia e emancipação, por esse motivo, confundiram-se. O pressuposto, deste ponto de vista, era que a Filosofia legislaria prática e politicamente e, por isso, o pathos seria deixado de lado.

Se concordarmos que o curso de filosofia segue o curso filosófico, e que é preciso um regresso à infância do pensamento, de que maneira tais ações se concretizam se, segundo nosso autor, os interesses estão fixados? Ou seja, "os alunos não estão dispostos à paciência, à anamnese, ao recomeço" ${ }^{\prime 109}$.

Podemos ir além, afirmando que o que está aí, aquilo que nos cerca, já parece dado desde sempre, naturalizado, banalizado, o que nos sugere algo mais danoso para o pensamento, ou seja, o que nos cerca, o que está diante de nós já está interpretado, dito. O que deve, então, fazer o professor de filosofia? Em primeiro lugar, J. F. Lyotard nos diz o que o professor não deve fazer, ou melhor, alerta para a maneira como o professor não deve ser instruído: "instruir os professores no sentido de que sejam conviviais, preconizar a sedução, prescrever que captem a indulgência das crianças através de estratégias demagógicas ou 'gadgets', é pior do que o mal"110. Ou seja, é preciso banir o aliciamento.

106. op. cit., p. 123.

107. Ibid.

108. Ibidem.

109. op. cit., p. 124.

110. Ibid. 
Qual a resistência que o curso filosófico pode criar? O mundo fala um idioma, o curso filosófico outro;

o mundo fala velocidade, gozo, narcisismo, competitividade, sucesso, realização. O mundo fala sob a regra da troca econômica, generalizada sob todos os aspectos da vida, incluindo as afeições e os prazeres. Esse idioma é completamente diferente do idioma do curso filosófico, é-lhe incomensurável. Não há juiz para decidir este diferendo. O aluno e o professor são vítimas um do outro. A dialéctica ou a dialógica não pode ocorrer entre eles, apenas a agonística ${ }^{111}$

A finalização da última carta, dá-se a partir de três observações que dizem respeito a algumas saídas para formar os professores de filosofia: a primeira invoca Aristóteles e suas retórica e dialética, considerando a escola como uma Ágora, logo o professor prepararia-se para a guerra das palavras, não necessariamente. Para I. Kant, segundo J. F. Lyotard, o filósofo seria como um guerreiro atento contra "os mercadores da aparência transcendental"112. Em seguida, há a saída platônica que aponta para a seleção dos espíritos e, finalmente, a pitagórica que separa os mathèmatikoi dos politikoi. O democratismo é rompido em favor de uma república dos espíritos. Diante dessas últimas saídas, "a Filosofia torna-se matéria de opção, ou é relegada para o superior, ou ensinada apenas em certos estabelecimentos do secundário. Tudo aponta para uma saída desse gênero, façamos o que fizermos"113. Contudo, o pessimismo que conduz J. F. Lyotard em suas últimas considerações, não é absoluto, já que ele afirma que mesmo rarefeita, a busca de anamnese, de elaboração, não desapareceu. E como fica o filósofo? Segundo ele, o filósofo deve desenvolver o seu curso para lá das questões esporádicas, ou dos modismos. É preciso, como nova tarefa do pensamento didático, "procurar a sua infância em qualquer parte, mesmo que seja fora da infância"114.

No início deste artigo dissemos que o objetivo deste trabalho era reunir considerações acerca de algumas cartas que J. F. Lyotard escreveu a propósito do debate pós-moderno em seu livro O pós-moderno explicado às crianças, relacionando-as com os argumentos da Condição pós-moderna para continuarmos verificando uma possível defesa de ruptura entre modernidade e pós-modernidade. Vimos, ao longo do artigo, que não há uma mudança considerável das regras do discurso científico na pós-modernidade, comparadas às da modernidade, elas apenas se constituíram mais explícitas, neste sentido, dissemos não haver ruptura.

111. op. cit., p. 125.

112. LYOTARD, J. F. 1997, p. 126.

113. Ibid.

114. Ibidem. 
Verificamos também que J. F. Lyotard pondera a favor, não de uma ruptura ou simples sucessão de épocas, mas declara existir uma nova direção depois da anterior. De uma noção de ruptura, baseada numa linearidade, própria da modernidade, J. F. Lyotard nos leva a perceber uma noção de re-arranjo entre aquilo que era essencial para a modernidade e o que é para a pós-modernidade. Além disso, nosso autor deixou claro que a pós-modernidade, ao invés de surgir de uma ruptura, é, antes de qualquer coisa, uma maneira de esquecer ou de reprimir o passado, ou seja, de o repetir, mais do que de o ultrapassar.

\section{Considerações finais}

Neste artigo, reunimos ponderações acerca de algumas cartas que J. F. Lyotard escreveu a propósito do debate pós-moderno em seu livro O pós-moderno explicado às crianças, neste texto o autor pressente que algo estava se transformando dentro da história contemporânea e, por essa razão, consideramos a discussão de tais textos valiosa para o processo de compreensão da condição pós-moderna. Ao longo dessas cartas J. F. Lyotard critica o totalitarismo e discute a questão da legitimidade.

J. F. Lyotard diz que a pós-modernidade impõe uma revisão da Aufklärung, ou seja, questiona a noção de um fim unitário da história e do sujeito. O que caracteriza a pós-modernidade é o acontecimento, representado pelo impresentificável, ou seja, não compete à pós-modernidade fornecer realidade, mas inventar alusões ao concebível que não pode ser presentificado. As metanarrativas sofrem com sua credibilidade, já que, para J. F. Lyotard, essas narrativas têm a função de legitimar, o que não impede, depois dos questionamentos acerca delas, que as mesmas tenham desaparecido.

Ao abordar a questão do totalitarismo, J. F. Lyotard o faz a partir do ponto de vista da linguagem da legitimação que, segundo ele, é mais radical do que qualquer outra, pois realiza-se sem recorrer a entidades, que frequentemente não interrogamos por negligência, como poder, sociedade, povo, tradição.

Em seguida, vimos que J. F. Lyotard afirma que o declínio dos ideais modernos trouxe com ele uma falência dos intelectuais. Na pós-modernidade estão inscritos esses erros. Sua luta foi contra a pseudo-racionalidade imposta pelo capitalismo, contra a performatividade. Mais adiante propõe observações que destacam alguns problemas relacionados com o termo "pós-moderno". A intenção não foi, segundo o autor, resolvê-los, mas procurar evitar confusões e ambiguidades. J. F. Lyotard entende o "pós" de "pós-modernismo", no sentido de uma simples sucessão, de uma sequência diacrônica de períodos em que cada um é, em si mesmo, claramente identificável. O 'pós' indica algo como uma conversão, uma nova direção depois da anterior. A ideia de linearidade é moderna e a modernidade correlaciona-se com a possibilidade e necessidade de rompimento com a tradição para instaurar uma maneira de viver e de pensar absolutamente 
nova. J. F. Lyotard diz supeitar de que a 'ruptura' é, antes de tudo, uma maneira de esquecer ou de reprimir o passado, ou seja, de o repetir, mais do que de o ultrapassar. Uma outra conotação do termo "pós-moderno" está filiada à desconfiança do princípio do progresso geral da humanidade, ideia que estava ligada à certeza de que o desenvolvimento do conhecimento resultaria no desenvolvimento da humanidade.

O Filósofo francês defende a ideia de que, longe de trazer progresso, as tecnociências aumentaram o mal-estar. As necessidades imediatas humanas não têm pertinência alguma para o progresso, cuja preocupação é numerizar.

Referindo-se à formação filosófica, J. F. Lyotard compreende que o curso filosófico trabalha a realidade afastando-se, principalmente, de um dos seus critérios que é 'ganhar tempo'. Essa é a grande dificuldade do professor de Filosofia, fugir dos valores imperativos dos desenvolvimentos, da 'performance', da velocidade, do contrato. No mundo pós-moderno o que importa é a velocidade, o gozo, o narcisismo, a competitividade, o sucesso, a realização. O mundo fala sob a regra da troca econômica, generalizada sob todos os aspectos da vida, incluindo as afeições e os prazeres.

\section{Referências Bibliográficas}

CAMPELO, Alexandre Lopes. A condição pós-moderna, segundo Jean François Lyotard: continuidade ou ruptura? Dissertação de Mestrado, Rio de Janeiro: UFRJ/IFCS, 2006.

DOS SANTOS, Roberval de Jesus Leone. Obsolescência da função do intelectual na modernidade. Revista Estudos Avançados da Universidade de São Paulo, volume 16, número 44, São Paulo, 2002.

LEVIN, Ira. Este mundo perfeito. Tradução Milton Persson; Rio de Janeiro - Editora Nova Fronteira, 1970.

LYOTARD, Jean-François. O pós-moderno explicado às crianças - correspondência 1982-1985. Tradução de Tereza Coelho. Lisboa, Publicações Dom Quixote, 2a edição, 1993.

LYOTARD, Jean-François. O inumano: considerações sobre o tempo. Tradução Ana Cristina Seabra e Elisabete Alexandre - Lisboa/Portugal, Editorial Estampa, 2a edição, 1997.

LYOTARD, Jean-François. A condição pós-moderna. Tradução: Ricardo Corrêa Barbosa; posfácio: Silviano Santiago. Rio de Janeiro: José Olympio, Rio de Janeiro, 2004 (7’ạ edição). 